\section{LAS REVISTAS FEMENINAS ESPAÑOLAS DEL SIGLO XIX. REIVINDICACIÓN, LITERATURA Y MODA}

\author{
M. a del Pilar Palomo Vázquez \\ Universidad Complutense de Madrid
}

\begin{abstract}
Cómo citar este artículo/Citation: Palomo Vázquez, M.P. (2014). "Las revistas femeninas españolas del siglo XIX. Reivindicación, literatura y moda". Arbor, 190 (767): a130. doi: http://dx.doi.org/10.3989/arbor.2014.767n3001
\end{abstract}

Recibido: 3 julio 2013. Aceptado: 6 abril 2014

RESUMEN: Se comentan las publicaciones periódicas del siglo XIX, dirigidas a la mujer. Tras un análisis cuantitativo del número de mujeres colaboradoras en prensa durante la centuria, se analizan las directrices generales de esas publicaciones. En la segunda parte se presentan ejemplos de su repercusión en autores coetáneos.

PALABRAS CLAVE: revistas femeninas; reivindicación; moda; presencia en autores coetáneos: Galdós, Valera, Bécquer.

I.- Escribía Juan Valera en El Correo de España, en 4 de agosto de 1897: “¿Quién si vale algo y si ha logrado alguna celebridad como escritor no ha sido o no es periodista en España?". Creo que se puede dar más amplitud a la pregunta y llegar a afirmar que todos los escritores del siglo XIX, con celebridad o sin llegar a alcanzarla, con asiduidad o esporádicamente, colaboraron en prensa. Pero la pregunta que hoy nos hacemos es por qué no se ha incluido en esa amplísima nómina a las mujeres, cuando se ha estudiado la literatura periodística del siglo XIX. Generalmente se han citado o analizado los artículos de aquellas escritoras que ya

\section{SPANISH WOMEN'S MAGAZINES OF THE 19TH CENTURY. DEMANDS, LITERATURE AND FASHION}

Copyright: (C) 2014 CSIC. Este es un artículo de acceso abierto distribuido bajo los términos de la licencia Creative Commons Attribution-Non Commercial (by-nc) Spain 3.0.

ABSTRACT: This article examines 19th Century periodical publications aimed at women. The article begins with a quantitative analysis of the number of women writers in the century and discusses the publications' general editorial guidelines. The second part of the article gives examples of their impact on their contemporaries.

KEYWORDS: women's magazines; demands; fashion; contemporaries: Galdós, Valera, Bécquer.

estaban en las historias de la literatura por sus novelas o su poesía, que, siempre, se anteponían a esa obra periodística, considerada menor. Es verdad que en las dos últimas décadas han surgido numerosos e importantes estudios críticos sobre este periodismo femenino del XIX, paralelamente al interés creciente sobre el feminismo y el rol de la mujer en la historia. ${ }^{1}$ Pero me parece inadmisible, aunque no me sorprenda, el silencio anterior, si consideramos que la presencia femenina en el periodismo del XIX, y la creación de revistas dedicadas a la mujer lectora, constituye un fenómeno social y literario de una magnitud que no 
podemos obviar. Y pienso que esta afirmación no necesita ser demostrada más que con la enumeración de unas cifras, que me apresuro a indicar. Cifras a las que he llegado tras una consulta de obras bibliográficas fundamentales. Primero los catálogos de dos autores inmersos en el mismo siglo XIX: el de Hartzenbusch, de 1870, y el de Ossorio y Bernard en 1903, y hoy día los trabajos de Carmen Simón y su monumental obra Mujeres escritoras del siglo XIX. Dedicadas a Carmen Simón, y en memoria de los citados críticos del XIX, presento hoy mis conclusiones.

En el citado manual bibliográfico de la doctora Simón Palmer se documenta la existencia de 4762 mujeres que, en mayor o en menor medida escribieron y publicaron durante la centuria. De ese sorprendente número, extraje aquellas escritoras que no publicaron en prensa. El resultado no es menos sorprendente: solo 350. Por tanto, el número de colaboradoras en periódicos o revistas sigue siendo abrumador: 4312. Presté atención, después, al perfil y contexto social de aquellas 350, y el resultado no fue, ahora, sorprendente en absoluto: un buen porcentaje de esas escritoras pertenecían a órdenes o asociaciones religiosas, y su obra, llamémosla extra-literaria, se desarrollaba en un círculo, si no contrario al periodismo, si muy alejado de él: biografías de santos, libros de devoción, etc... Podían ser testimonio, en ocasiones, de una muy interesante actividad intelectual, pero esa actitud (desarrollada dentro del claustro muchas veces) no se vinculaba con el amplísimo espectro social del periodismo. No nos imaginamos colaborando en la prensa, por ejemplo, a la Vizcondesa de Jorbalán - María Micaela del Santísimo Sacramento, fundadora de las Adoratrices y canonizada en 1934. En mayor número, entre esas 350 excepciones, aparecen las profesoras adscritas estatalmente a la enseñanza, que escriben libros o folletos vinculados científicamente con su profesión, desde un tratado de matemáticas o geología a manuales de bordado. Y por último, un numeroso sector de escritoras ocasionales, (anotadas por la minuciosa Carmen Simón), que figuran con un solo texto, recogido en Álbumes poéticos, Certámenes, Homenajes, etc.

Examinando la labor de esas 4312 que nutrieron el periodismo decimonónico, llegué a otro porcentaje que estimo aún más revelador para situarnos en la adscripción al periodismo de un número de mujeres, auténticas pioneras, y dignas de figurar en cualquier estudio que pretenda estudiar la historia del feminismo en España. Me refiero a las cerca de 50 mujeres (he contado 47, pero supongo que fueron más) que fundaron, fueron propietarias y dirigieron periódicos o revistas en el periodo que transcurre desde 1833, aproximadamente, ya durante la regencia de Maria Cristina, hasta finales de siglo. Muchas de ellas están presentes en los importantes ejemplos que se han seleccionado para ser motivo de nuestra atención y no me detengo en ellas, porque han sido objeto de estudio en el presente volumen: Serrano de Tornel, Ángela Grassi, Gómez de Avellaneda, Pilar Sinués, etc.

Entre todas estas consideraciones, más cuantitativas que analíticas, debo añadir una que también considero significativa, como es la indagación de qué revistas ofrecen mayor número de colaboradoras, no de colaboraciones. He llegado a ese dato a través del "Índice de publicaciones periódicas citadas", del tan utilizado estudio de Carmen Simón y dividiendo el número de escritoras con más numerosos textos aparecidos en cada revista, por el número de años de vida de la publicación en que se encuentran, he llegado a delimitar las cinco revistas, cuyas páginas ofrecen un mayor número de textos escritos por mujeres. Las cito por orden de mayor a menor número: El Correo de la Moda, muy por delante del resto (dirigida por Ángela Grassi y luego por Joaquina García Balmaseda), El Álbum Ibero Americano (dirigido por Concepción Jimeno de Flaquer), Flores y Perlas, (dirigido por Pilar Sinués), La Violeta (dirigida por Faustina Sáez de Melgar) y La Madre de Familia (dirigida por Enriqueta Lozano). Es decir que las cinco revistas en que con una mayor asiduidad escribieron las escritoras del XIX estaban dirigidas por mujeres. No comento el dato, pero pienso que podrían sacarse de él conclusiones interesantes, de tipo sociológico.

A estos números previos, tengo que añadir que desde 1813 (fecha de la primera publicación) a 1899, aparecieron en España más de 100 revistas dedicadas, explícitamente, a la mujer lectora. Que a esas revistas dedicadas al "bello sexo" (como denominan al sexo femenino muchísimas de ellas) habrían de añadirse las que lo hacen implícitamente, me refiero a las publicaciones dirigidas a los niños (más de 30 ), ya que, de carácter evidentemente educativo, en realidad están dirigidas a sus educadoras básicas. O las dedicadas a la familia, por razones similares, aunque aquí el número sería ampliable con cualquier otra revista "pintoresca", es decir con ilustraciones. Recordemos cómo Mesonero Romanos, titulaba un grabado de su revista (de 6 de enero de 1839): "Semanario Pintoresco Español. Lectura de las familias".

Sin embargo, dentro de su tono general de un mensaje dirigido a la mujer conservadora, inmersa en una 
sociedad patriarcal casi siempre asumida, sí quiero comentar algunos casos que pueden parecernos insólitos dentro de ese prejuicio establecido. De antemano, tendremos que tener en cuenta que en una buena parte de esas llamadas revistas femeninas, entre labores y moda elegante, subyace en sus textos y en sus propósitos un interés por promover la educación de la mujer. $Y$ que en muchas de esas revistas, y en sus directoras o colaboradoras (o directores y colaboradores) existe un auténtico movimiento reivindicativo. Y pienso, por ejemplo, en la labor de Amalia Domingo Soler o de la radical librepensadora Rosario de Acuña.

Así, en esa línea, existen revistas como La llustración de la Mujer (Barcelona, 1883), dirigida por Carlos Frontaura, que en su artículo inicial declara la intención de la publicación: "contribuir a la redención social del bello sexo", ya que "puede tener el hombre mayor cantidad de cerebro, pero no mejor calidad, que es lo que importa". O el Álbum del bello sexo, (Barcelona, 1882), subtitulado "Órgano de la emancipación de la mujer", dirigido por Luisa de Sáñez, en donde se defiende "la igualdad de derechos entre el hombre y la mujer, ya que los deberes de esta son superiores a los de aquel". ${ }^{2}$ Y creo que en este tono de defensa de la posición intelectual de la mujer, hemos de colocar aquellas revistas en donde las escritoras señalan que han sido únicamente ellas sus creadoras. Así Gaceta de las mujeres (Madrid, 1845), dirigida por la Avellaneda, que ofrece como subtítulo la tajante afirmación de que está "Redactada por ellas mismas", aunque no se cumpliese totalmente el propósito, ya que aparecen también colaboradores masculinos. Pero sí se cumplió en La Mujer (Madrid, 1851), "Periódico escrito por una sociedad de señoras y dedicado a su sexo", donde, al parecer, solo colaboraron mujeres.

Acentuando ese tono reivindicativo, se dan casos extremos, como la revista Ellas, objeto de un estudio en el presente volumen. Pero hay bastantes otros casos igualmente representativos. Pienso, por ejemplo, en alguna publicación de carácter considerado entonces subversivo, La conciencia libre, dirigida por Belén Larraga de Ferrero, espiritista, propagandista, revolucionaria y republicana que, incluso, fue encarcelada en Valencia por sus ataques al gobierno, desde su revista, ante la crisis del 98. El tono de acusación social desde su publicación se evidencia desde la portada, donde junto a su título aparecen dos lemas bien expresivos: "iGuerra a la hipocresía y a la ignorancia!" y “iPaso a la ciencia y a la verdad!", junto al grabado de una figura de hombre, que adivinamos como proletario por su atuendo, sentado sobre un yunque, con un letrero en él: "Trabajo y ley para todos". O mucho más escandaloso, a causa de su directora, El León, aparecido en Madrid en 1870, subtitulado "Periódico político y satírico moral" dirigido por Mina PuccineIla. Evidentemente nos encontramos ante una autora no hispánica. Pero su figura no puedo pasarla por alto. Hartzensbusch (cuyo catálogo consigna revistas, no escritores) se limita a definir el periódico que esta dama dirigía como "republicano federal". Pero Ossorio nos trasmite la siguiente nota sobre la periodista: "Amazona italiana que acompañó a Garibaldi en muchas de sus empresas revolucionarias. En 1870 residía en Madrid, vistiendo traje masculino y dirigiendo $E I$ León, periódico político y satírico universal". Imaginemos a esta garibaldina en el Madrid de 1870.

Pero esas revistas no "femeninas", aunque dirigidas por mujeres, no podemos adscribirlas únicamente a una ideología política de justificada protesta social, ya que también podían encauzar sus esfuerzos a la difusión de temas artísticos y culturales. Así Asta Regia (Jeréz de la Frontera, 1879), dirigida por Carolina de Soto, no omite en sus páginas el capítulo "modas" (que era además usual en cualquier revista ilustrada) pero dedica su esfuerzo al estudio del arte y las costumbres locales. O, sobre todo, El Phartenón, (BarceIona, 1880), fundado y dirigido por una mujer excepcional, Josefa Pujol. Escribió sobre temas de la mujer y, como sus compañeras periodistas, fundó revistas "femeninas" como La Moda Europea, y dirigió durante un tiempo Flores y Perlas. Pero Josefa Pujol fue una conocida helenista, especializada en temas grecoromanos. Consecuencia de esa formación (insólita en una mujer de su siglo) fundó El Phartenón, donde debajo de un grabado clasicista, delimita el contenido de la publicación: "Revista de literatura, Ciencias y Artes". En sus páginas, obviamente, colaboraban los principales autores coetáneos: Castelar, Alarcón, Nuñez de Arce, Pérez Galdós... junto a escasas colaboradoras femeninas: Julia Asensi, Concepción Jimeno de Flaquer o Carolina Soto.

Este propósito cultural no era, sin embargo, algo ajeno a las llamadas "revistas femeninas", ya que la tendencia general en ellas, de feminismo reivindicativo o no, era la necesidad de dotar a la mujer de una educación que fuera más allá de sus tradicionales labores domésticas, aunque también se atiende a estas en sus páginas. Las llamadas de atención a esa necesidad educativa son constantes. En La Mujer (Madrid, 1871) que dirigió Faustina Sáez de Melgar, y que se subtitula "Revista de interés general del bello sexo", se asegura que la mujer "no debe permanecer más 
tiempo en las tinieblas de la ignorancia". Y no solo por ella, ya que en otra publicación similar La Educación de la Mujer (Barcelona, 1877) de un intencionado mayor espectro social, se afirmará: "La salvación, la civilización, la felicidad del hombre, de la sociedad, está indefectiblemente en la educación de la mujer"3. Pensemos que existió, incluso, una Asociación para la enseñanza de la mujer, cuyo órgano fue la revista Instrucción para la mujer, ya de 1882. Y a finales del $\mathrm{XIX}$, encontraremos una revista, La escuela moderna, de gran contenido cultural, con importantes artículos sobre el feminismo en España, y donde se defiende el acceso de la mujer a profesiones liberales, tradicional y legislativamente prohibidas para ella. Sin embargo, ese evidente anhelo dignificador que, sinuosamente, subyace hasta en las revistas de moda (que también, no podemos olvidarlo, fueron revistas literarias), no nos parece tan altruista: ¿Se intenta promover la educación de la mujer para dignificarla, en sí misma? ¿ se intenta que ejerza mejor su rol social de madre de familia? ¿Ser mejores ellas mismas, para alcanzar la actividad social o laboral que les está vedada? ¿O ser un instrumento de mejora social, pero sin salirse, eso sí, del papel que la tradición y las leyes le han impuesto? Porque muchas de esas defensas aparentemente feministas son, al menos, sospechosas. Pensemos en alguna de ellas. El sacerdocio de la mujer (Barcelona, 1886) es una publicación encaminada "a la educación de la mujer". Pero esta parece que debe ser, únicamente, como ideal de ese "sacerdocio", la "respetuosa hija, digna esposa y cariñosa madre". O El Álbum de la Mujer (Barcelona, 1898), donde se definen así los deberes y derechos de la misma: "La dulce caricia del hijo de vuestras entrañas; el amoroso afán de vuestro esposo; ese es vuestro derecho. El noble respeto y entrañable amor a este, la tierna solicitud y el constante amparo de aquel: ese es vuestro deber". ${ }^{4}$ Pero creo más significativo el ejemplo que ofrece EI Defensor del Bello Sexo (Madrid, 1845), que se subtitula "Periódico de literatura, moral, ciencias y moda, dedicado exclusivamente a las mujeres". Ya la portada es reveladora. Aparece una dama flanqueada por dos círculos en donde leemos: Castidad. Pudor. Sensibilidad. Beneficencia. Y en el artículo con que se inicia la publicación (titulado "Ideología"), el autor aboga por la educación femenina, pero añade: "Y no se crea por esto que en nuestro sentir el bello sexo deba de ser educado para la cátedra y discusiones políticas. No. Nos disgustan los extremos: ni nos parece que se le debe dejar en un completo abandono, ni consideramos tampoco que le sea lícito invadir las atribuciones que por la naturaleza y las leyes nos están concedi- das". Educación ma non troppo. En realidad estamos ante un debate social, del que no estuvieron ausentes las revistas femeninas. Porque esta opinión llamémosla moderada, es la sustentada por una buena parte de la sociedad como tuve ya ocasión de estudiar en algún trabajo anterior (Palomo, 2012). No podemos olvidar que un sector de esas colaboradoras y lectoras de prensa femenina participarían de esa opinión de no "invadir" el campo laboral masculino. Por ejemplo, un artículo publicado en La Madre de Familia, en 1876, firmado por Adela Sánchez Carlos, se titula “Un problema social" y es un auténtico alegato en contra de esa emancipación laboral femenina: solo las artes y la literatura son tareas compatibles con los deberes de la mujer. Pero esos deberes siempre, a lo largo de la historia, fueron compatibles con la lectura y prácticamente todas las revistas dedicadas a la mujer se la ofrecían: novelas, cuentos y poesía, mucha poesía. Pienso que la posible lectora se convertiría con frecuencia en oyente, si pensamos en la práctica habitual de la lectura en familia, y cuando encuentro un título revelador: Las veladas del hogar, de 1867. En él se alude, sin duda alguna, a ese espacio temporal de las noches familiares, en que un lector o lectora había deleitado a unos oyentes, desde los libros de caballería hasta los folletones de la prensa decimonónica. Y las periodistas que nos ocupan contribuyeron a ello, tanto en las revistas dirigidas al "bello sexo" como en todas las demás, que estuvieron, por supuesto, abiertas a sus colaboraciones. Incluso las menos "femeninas". Pienso, por ejemplo, en La caza, subtitulada "Revista de cazadores", donde fue redactora Sofía Tartilán. Y recordemos, entre tantos ejemplos, que la primera edición de La Gaviota, de Fernán Caballero, apareció en El Heraldo.

II.- Deteniéndome ahora, someramente, en el contenido y estructura de las revistas, comienzo por algo bien sabido y es que, su receptor femenino venía ya indicado, por lo general, en el mismo título. Desde el inicial periódico, El amigo de las damas, (Cádiz, 1813), los términos "damas", "mujer" o "bello sexo", rotulaban la publicación. En 1822, apareció el que se consideró durante largo tiempo el iniciador: El periódico de las damas, que fue, asimismo, el pionero del contenido habitual de las publicaciones destinadas a la mujer. Pero ese receptor, en realidad receptora, venía, además, bien recalcado en los reveladores subtítulos, donde se especificaba, generalmente, contenido, intención y destinatario.

Pienso que en los casos en que el título no denotase ese receptor femenino, el comprador, suscriptor (o in- 
vestigador actual), no podría saber, de antemano, de ese carácter de revista femenina. Recordemos, entre muchos ejemplos, El Ateneo de Madrid, de 1859, que inmediatamente nos aclara, y muy concretamente en este caso, a quién se dirige y qué contiene: "Revista quincenal de literatura y bellas artes, dedicada a las damas de la aristocracia española". O Extremadura literaria (Badajoz 1889), donde leemos, bajo este título que indica un contenido pero no un receptor; "Revista semanal dedicada al bello sexo". Los ejemplos son numerosísimos: El trovador del Ebro (Zaragoza, 1869), La Guirnalda (Madrid, 1867) La Aurora (Santa Cruz de Tenerife, 1873), La Floresta (Barcelona. 1857), El Vergel de Andalucía (Córdoba 1845), Calipso (Madrid 1843), La Psiquis (Valencia, 1840), etc... Pero la importancia de esos subtítulos, radica tanto en el esclarecimiento, a priori, de su receptor, como de la existencia de un contenido generalizado, ya que en ellos aparecen, machaconamente, dos términos que delimitan su temática principal: literatura y moda. Así se consigna en La Violeta (Madrid, 1862), El Cupido (1842), La Sílfide (Madrid, 1845), La Mariposa (1839) y un, de nuevo, largo etcétera. Y cuando el término moda ya aparece en el título, su compañero, literatura, aparecerá en el subtítulo casi generalmente. Al menos en las revistas que alcanzaron mayor difusión en tiempo y en espacio. Como ejemplo, baste consignar El Correo de la Moda, que, desde 1851, aclaraba en su subtítulo "Periódico del bello sexo. Modas, Literatura, Bellas Artes, Teatros, etcétera.", que más tarde se condensó en "Periódico de modas, labores y literatura".

La simbiosis Moda y Literatura venía ya consolidada desde la pionera publicación El Periódico de las Damas que comenzó con el innovador atractivo (en España) de acompañar la publicación con figurines en láminas aparte, que procedían de L'Observateure des Modes parisino, uno de los herederos del pionero Journal des Dames et des Modes (1797- 1839). Pero junto al atractivo de esos figurines, el periódico ofrecía, por ejemplo, una sección de poesía, a cargo de un anónimo autor que firmaba con el pseudónimo de $E I$ Poeta del periódico.

El modelo se repitió incansablemente, incluida la procedencia francesa de patrones y figurines. Incluso en alguna publicación (entre otras muchas) como La Mariposa (Madrid, 1839), esa procedencia francesa de los modelos ofrecidos se aducía como una justificación de lo que podía entenderse como un alarde de lujo provocativo, ante la difícil situación por la que atravesaba España (Guerra Carlista), y la "Introducción" al primer número se acoge a la evasiva de que serán simplemente "el eco de una moda extranjera", que, además, están siguiendo "todas las naciones de la culta Europa". En consecuencia, se recalca esa procedencia, y en los primeros nueve números de la revista, los textos sobre moda, anónimos, se adscriben a un "corresponsal" que los envía desde París. Y cuando esta localización desaparece y se rastrean en ellos unos espacios madrileños, siempre se esforzará el anónimo comentarista en "anunciar cuanto antes los últimos modelos de París" (no 21, de 30 de Octubre de 1839). Y la moda, esa "deidad que todo lo avasalla", y a quien se rinden "todas las potestades de la tierra" (n14, de 20 de Agosto), conservará su cetro parisino durante toda la centuria. Aquellos figurines del XIX, bellísimos, que acompañan a las revistas femeninas, han nutrido, en buena parte, el fondo artístico de anticuarios y coleccionistas. Y fue, sin duda, uno de los grandes atractivos de las publicaciones que, por lo general, ofrecían, en grabados de madera, en blanco y negro, impresos con el texto, una abundancia increíble de modelos de trajes y accesorios. Pero las láminas en color (que luego podían encuadernarse con la publicación) eran lo más selecto y, por supuesto, lo más caro de la revista. Nos lo revela, por ejemplo, el hecho de que esta aumentaba de precio, cuando aumentaba el número de figurines y patrones (el caso de El Tocador (Madrid, 1844)), o incluso el aviso en alguna otra de una sustanciosa rebaja en la suscripción si se renunciaba a ellos. Todo ello indica (nos basta contemplar los figurines) que las revistas se dirigían a una clase social aristocrática o acomodada. Pero anotemos, también, que una parte de ellas se dirigían, expresamente, a sastres y modistas, como El Figurín (Madrid, 1878), El Arte Español (Madrid, 1871) e incluso, muy explícitamente, a un sector determinado del arte de la confección, como El Buen Tono (Madrid, 1849), que aclara así su proyecto editorial: "Revista de moda, arte e industria. Periódico mensual dedicado a los sastres y fabricantes de sombreros".

Sobre el importantísimo aporte literario de las revistas femeninas (poesía, novela, cuento, artículo) no voy a insistir, porque en buena medida se analiza en otros textos del presente volumen. Pero sí quiero dedicar una última parte de mi trabajo a comentar el interés que estas publicaciones suscitaban en los lectores masculinos, como lo manifiestan algunas novelas de relevantes autores del momento.

Asombra, por ejemplo, la minuciosidad descriptiva y conocimiento del léxico de la moda en un Galdós. Recordemos la descripción pormenorizada del vestido y complementos de María Egipciaca en La familia de 
León Roch, cuando se engalana para ir a reconquistar a su marido (cap. XIV y XV), en que no falta ni el detalle del color azul de las medias, según dictaba la moda del momento, o la casi inevitable alusión a una manteleta cortada por un "discípulo de Worth". Y deberé volver en páginas posteriores al célebre modisto, a cuyo taller parisino acudirá la Eloísa de Lo prohibido para traerse a Madrid las últimas novedades (cap. IX, II). Pero será en La de Bringas, donde Galdós despliega tal conocimiento del léxico y las formas de la indumentaria femenina en torno a 1867-68, años en que transcurre la acción, que creo necesario suponer una previa información en una lectura, muy bien aprovechada, de revistas femeninas coetáneas a esas fechas. La protagonista de La de Bringas sufre una "embriaguez de trapos", según califica Galdós su obsesiva afición a poseer y lucir las telas y prendas más lujosas y nuevas que ofrecían los establecimientos madrileños, que las importaban de París. Obsesión que llevará a la señora de Bringas a una ruina económica y moral. Y contextualizando acción y personaje, en los diálogos o en la narración se citan numerosísimos términos del mundo de la costura y la moda que son otros tantos galicismos introducidos en nuestro idioma, perdidos unos pero mantenidos otros hasta hoy día. ${ }^{5} \mathrm{Y}$ escribe Galdós: "Los términos franceses que matizaban este coloquio se despejaban del tejido de nuestra lengua; pero aunque sea clavándolos con alfileres, los he de sujetar para que el exótico idioma de los trapos no pierda su genialidad castiza" (cap. X). Sabemos de la continua utilización de Galdós de la prensa para desarrollar sus narraciones. ¿Y dónde podía aprender mejor ese aludido "idioma de les trapos" sino en las revistas que dedicaban a ellos una parte importantísima de sus textos y grabados?

Pero recordemos, alejándonos de toda banalidad, que Galdós manifestó su interés por el tema (en su discurso de ingreso en la Real Academia Española) cuando asegura que "la vestidura" es la que "diseña los últimos trazos externos de la personalidad", en parangón con todo aquello que constituye la "materia novelable" que ofrece el estudio de la sociedad. El traje como signo, que tanto se ha analizado en los estudios de orientación semiológica. En consecuencia, no nos puede extrañar su interés por el tema y el significado que el traje de sus personajes adquiere en sus novelas. Sabemos, por otra parte, que tenía en su biblioteca una colección casi completa, del ya aludido Periódico de las Damas, de 1820.

Pero, además, puedo ofrecer un testimonio de la utilización de un artículo sobre moda (Palomo, 2008) que salta del Seminario Pintoresco Español, de 15 de mayo de 1836, a las páginas de La Estafeta Romántica, cuya acción comienza en "septiembre del año 35". Se trata de un texto denominado Modas dedicado a las novedades que ha traído el famoso sastre Utrilla, importadas de Londres. En los comienzos de la novela, al joven Calpena, el protagonista, le encargan un vestuario completo, y Galdós, casi literalmente, traspasa la lista que ofrece el artículo a la descripción enumerativa de dicho vestuario. Y cuando los Episodios Nacionales prosiguen, y nuevas notas sobre moda se suceden, estas aparecen en textos posteriores del Semanario, señaladas al margen con lápiz azul por el propio Galdós, en la colección que tenía en su biblioteca. Y es evidente que buena parte de las noticias sobre moda que aparecen en Mendizábal podríamos encontrarlas en las publicaciones femeninas coetáneas a la acción. Pienso en el Correo de las Damas, cuyos figurines está rompiendo un niño en Los Apostólicos, travesura por la que le castigan.

Pero las revistas femeninas no solo fueron asiduamente leídas por nuestros grandes escritores de la etapa realista (era un fenómeno social ante el que no permanecieron ajenos) sino que en alguna ocasión una de aquellas revistas pudo determinar el desarrollo de una trama novelesca. Y voy a referirme a la conocida obra Juanita la Larga, de Juan Valera, que apareció como folletín en El Imparcial en 1895 y en forma de libro al año siguiente. En ella, recordémoslo, el escritor cordobés relata las circunstancias de los amores entre un bien conservado cincuentón y una muchacha de muy baja condición social y de menos de veinte años. La acción transcurre en Villalegre, nombre ficticio de un pueblo de la campiña cordobesa. Juanita es hija de Juana la Larga, humilde modista del pueblo (amén de otras habilidades) y la primera sorpresa del lector es cuando se nos dice que Juana (y luego su hija), "cortaba vestidos, con tanto arte y primor como Worth o la Doucet en la capital de Francia" (cap. III). A ningún lector o lectora le pudo parecer verosímil la afirmación: de todos y todas era conocido que Worth era el principal modisto europeo y que su taller, en París, era el foco de donde irradiaba toda la moda europea dirigida, por supuesto, a la alta sociedad. Su fama fue extraordinaria, sobre todo, cuando se convirtió en el modisto preferido, casi exclusivo, de la emperatriz, la española Eugenia de Montijo. Por supuesto fue hasta un honor, para la aristocracia europea, o damas pertenecientes, por dinero o clase, a la alta sociedad, vestirse en el taller del gran Worth. Cuando este murió en 
1895, La llustración Española y Americana publicó su retrato y una sucinta nota biográfica acompañando el grabado. Pero cuando Valera redacta su novela, Worth aún vive y sigue siendo el nombre indiscutible de la moda europea.

¿Worth en Villalegre?, se preguntaría el lector. Pero Valera sabe bien lo que escribe, y capítulos después aclara el aparente misterio. Porque cuando Juana y Juanita quieren obsequiar a don Paco, propone la madre a la hija: "...vamos tú y yo a hacerle una levita nueva, según el último figurín de La Moda Elegante e Ilustrada que recibiste de Madrid el otro día." (cap. XIII).

Así era como Worth y los diseños franceses entraban en el taller de la modista pueblerina. $Y$ ya tenemos toda la clase elevada de un pueblo cordobés vestida a lo Worth, porque Juanita, escribe Valera, "estaba al corriente de las últimas modas de París, que recibía los figurines, y que, ajustándose a ellos, sin encadenar servilmente su fantasía a una imitación minuciosa, ideaba, trazaba, cortaba y hacia trajes para las mujeres dignos de figurar en los salones de la Corte y de ser descritos por Montecristo o por Asmodeo", (cap. XXIII), seudónimos de los principales cronistas de salones del momento. Y la perfección y elegancia se extendía a los trajes de niños, que paseaban por Villalegre como si fueran "la prole de un milord o de un banquero inglés." Pero, para convencer de la verosimilitud de esta estampa inaudita, añade Valera, con la fórmula de comunicación directa con el lector que le es habitual:

"Ruego al lector que me dé entero crédito y que no imagine que son ponderaciones andaluzas, y que mis simpatías hacia Juanita me ciegan. Lo que digo es la verdad exacta, pura y no exagerada. Yo he estado en Villalegre, he visto alguno de los trajes hechos por Juanita, y me he quedado estupefacto. Y cuenta que yo tengo buen gusto. Todo el mundo lo sabe"

Ninguna de las dos irónicas observaciones finales puede ponerse en duda. El buen gusto del aristócrata, cosmopolita y seductor diplomático que fue Valera, era proverbial. Y lo sabía toda Europa y parte de América, tras su paso, como diplomático, por los más selectos salones de Nápoles, Lisboa, Brasil, Dresde, San Petersburgo, Franckfurt, Washington, Bruselas y Viena.

Pero he aludido a que la citada revista, motivando la asombrosa elegancia de la propia Juanita, fue determinante en la trama. Porque cuando la muchacha acepta de don Paco un lujosísimo corte de traje, de espléndida seda verde, se confecciona un modelo a la última, y se presenta con él en la misa mayor de las fiestas patronales, se organiza tal escándalo que hasta el cura desde el púlpito arremete contra ella, por salirse de su esfera social. Y ello dará motivo a un giro esencial en la trama del relato, cuando, ante el bochorno sufrido, Juanita cambia totalmente la estrategia de su actuación. Los figurines de La Moda Elegante e llustrada fueron, a la postre, el origen del triunfo final de Juanita que, casada con don Paco podrá, en lo sucesivo, lucir cuantos trajes de seda se le antojen.

Todo lo anterior creo que prueba suficientemente la existencia de un público lector masculino. Y aunque sea obvio volver sobre ello, recalquemos la existencia en las diferentes revistas femeninas de incesantes colaboraciones de los mejores escritores masculinos del siglo. De hecho, en el comienzo, estas publicaciones dirigidas al "bello sexo", estuvieron dirigidas y escritas por varones. Pero quiero dedicar, como apartado final, la presencia en ellas (en compañía de tan numerosas mujeres como hemos comentado) de nombres casi paradigmáticos en el panorama de la literatura española. Y voy a referirme a tres escritores que no ofrecen duda cuando los consideramos los iniciadores de la modernidad, en el periodismo, la novela o la poesía. Me refiero, naturalmente a Larra, Galdós y Bécquer.

De Pérez Galdós creo que basta con consignar que varias de sus novelas (La familia de León Roch, El doctor Centeno...) fueron publicadas como fascículos o folletones en La Madre y el Niño o La Guirnalda. De Larra recordemos que fue colaborador asiduo de EI Correo de las Damas durante el año 1833. Pero creo que la publicación de una Rima del poeta sevillano en El Correo de la Moda, merece una detención.

Que Bécquer prestó atención a la mujer lectora y a la moda, no puede ponerse en duda. Respecto a lo primero, recordemos el manuscrito donde esbozó una serie de proyectos editoriales (Bécquer, 2007, p.1627) que, naturalmente, no pudo realizar. En ellos encontramos la síntesis de una "Biblioteca del tocador", una colección de "novelitas" en lujosísimas encuadernaciones dirigidas a la mujer aristocrática. Y junto a ella, una "Biblioteca del Bello Sexo", en una más modesta presentación, constituida por obras escritas por mujeres, de Safo en adelante.

En cuanto a la moda, basta leer las crónicas de sociedad publicadas en El Contemporáneo, en 7 y 8 de febrero de 1864: "Revista de salones" y "Bailes y bailes". Su descripción de los trajes y tocados de las 
damas asistentes, son dignas del mejor comentarista de modas, sin que falte, además, en ellas, algún rasgo que revela al poeta. Pero lo más importante es que al final del segundo texto, manifiesta el entusiasmo con que ejerce esa tarea de describir "un mundo encantador"..."de tules, gasas y aderezos y coronas de flores..."

¿Puede extrañarnos, pues, que Bécquer publicase en 1860 una de sus Rimas más significativas en El Álbum de Señoritas y Correo de la Moda? Se trata de la Rima $X V$, según el número que le asigna la edición póstuma de sus obras, en 1871. En esta primera versión (no me detengo en sus posteriores y mínimas variantes) figura con el título de Tú y yo. Melodía, suprimido en el manuscrito llamado Libro de los gorriones, realizado dos años antes de su muerte. ${ }^{6}$ La Rima XV es la primera que conocemos donde Bécquer apunta su gran metáfora metapoética: la imposibilidad de fusión de un tú y un yo, porque el yo es el poeta que intenta inútilmente poseer a la amada, que es la poesía. Recordémoslo. Muchas otras Rimas volverán a comunicarnos ese concepto, que le lleva a considerar que el perfecto poema (que es lenguaje y forma) sería el que pudiese comunicar la poesía, que es sentimiento. Porque el poema está hecho con palabras, es producto de la razón, y solo el genio es capaz de domar "el rebelde y mezquino idioma". Las Rimas no son, en su sentido más profundo, la confesión autobiográfica de unos amores desdichados. "Yo, cuando siento, no escribo", nos dirá Bécquer en sus "Cartas literarias a una mujer". Son una gran metáfora (estamos en la órbita de Baudelaire, Verlaine o Rimbaud) que nos abre la puerta de la poesía española contemporánea. De 1860 hasta hoy. Y es bonito pensar que ese primer escalón lo encontremos en una de esas revistas femeninas que he procurado comentar.

\section{NOTAS}

1 Entre otras aportaciones, véanse los trabajos de Jiménez Morell (1992), Roig (1990), Sánchez Llama (2000), Caballé (2013). En la actualidad, Carmen Servén dirige un equipo de investigación en la Universidad Autónoma de Madrid, sobre las revistas femeninas de la segunda mitad del siglo XIX.

2 Ambos textos citados a través de C. Simón (1975)

\section{BIBLIOGRAFÍA}

Bécquer, G. A. (2007). Obras completas. Edición, introducción y notas de J. Estruch. Madrid: Cátedra.

Bécquer, G. A. (1977). Libro de los Gorriones. Edición, introducción y notas de M.P. Palomo. Madrid: Cupsa editorial.

Caballé, A. (2013). El feminismo en España. La lenta conquista de un derecho. Madrid: Cátedra.

Hartzenbusch, E. (1894). Apuntes para un catálogo de periódicos madrileños desde el año 1661 al 1870. Madrid: Establecimiento tipográfico "Sucesores de Ribadeneyra".
3 Ambos textos citados a través de C. Simón (1975).

4 Texto citado a través de C. Simón (1975).

5 Por ejemplo: foulard, gross glasé, encajes valenciennes, pouff, retroussé, ruché (cap. X), poplín por popelín (cap. XV), entredós, maragout (cap. XVI), aigrette, fichú (cap. XVI), etc. Se citan los colores de moda, como el cenizas de rosa (cap. $\mathrm{X}$ ) o se alude y describen la casaca guardia francesa (cap. XVI) o la casaca Watteau (cap. XXI).

6 Bécquer (1977)
Jiménez Morell, I. (1992). La prensa femenina en España (desde sus orígenes a 1868). Madrid: Ediciones de la Torre.

Ossorio y Bernal, M. (1903). Ensayo de un catálogo de periodistas españoles del siglo XIX. Madrid: Imprenta y litografía de J. Palacios.

Palomo, M.P. (2008). Larra, Galdós y el periodismo romántico. Isidora. Revista de Estudios Galdosianos, 6, pp. 5-23.

Palomo, M.P. (2012). "La imagen de la mujer en el Semanario Pintoresco Español". Arbor, vol. 188, no 757, pp. 937-844. http://dx.doi.org/10.3989/ arbor.2012.757n5008
Roig, M. (1990). La mujer en la historia a través de la prensa. Francia, Italia y España. Siglos XVIII-XIX. Madrid: Instituto de la Mujer.

Sánchez Llama, I. (2000). Galería de escritoras isabelinas. La prensa periódica entre 1833 y 1895. Valencia: Cátedra.

Simón Palmer, C. (1975). "Revistas españolas femeninas del siglo XIX". Homenaje a D. Agustín Millares Carlo, tomo I, Las Palmas: Cajas de Ahorro, pp. 401-445.

Simón Palmer, C. (1991). Escritoras españolas del siglo XIX. Manual bio-bibliográfico. Madrid: Castalia.

Simón Palmer, C. (1993). Revistas femeninas madrileñas. Madrid: Artes Gráficas Municipales. 